Branco J.M., Sousa H.S., Lourenço P.B. (2016) Experimental analysis of Maritime pine and Iroko single shear dowel-type connections, Construction and Building Materials 111. pp 440-449 (doi.org/10.1016/j.conbuildmat.2016.02.134)

The final publication is available at sciencedirect.com: http://doi.org/10.1016/j.conbuildmat.2016.02.134

\title{
Experimental analysis of Maritime pine and Iroko single
}

\section{shear dowel-type connections}

Jorge M. Branco ${ }^{1^{*}}$, Hélder S. Sousa ${ }^{1}$, Paulo B. Lourenço ${ }^{1}$

1 ISISE, Department of Civil Engineering, University of Minho, 4800-058 Guimarães, Portugal

e-mail addresses: Jorge M. Branco - jbranco@civil.uminho.pt

Hélder S. Sousa - sousa.hms@gmail.com

Paulo B. Lourenço - pbl@ civil.uminho.pt

* corresponding author: ISISE, University of Minho, Department of Civil Engineering, Azurém, 4800-058 Guimarães, Portugal; e-mail: jbranco@civil.uminho.pt

Tel: +351 253510200; Fax: +351253510217

\section{ABSTRACT}

In this study, screwed connections were experimentally evaluated, checking the plausibility of Eurocode 5 for two selected wood species, Iroko (Milícia excelsa) and Maritime pine (Pinus pinaster). Single shear screwed connections, considering self-tapping screws, were tested and the experimental campaign aimed at evaluating various mechanisms of resistance suggested by Eurocode 5 for this typology of connection, including axial withdrawal capacity of the screw, pull through parameter for screws, and local embedment of wood. The experimental 
results evidenced that the analyzed connection system had similar results with either wood species. The results were consistent with the calculation through Eurocode 5.

KEYWORDS: Screwed connections, experimental evaluation, Maritime pine, Iroko

\section{INTRODUCTION}

In timber structures, connections are weak regions as they represent a reduction of continuity and strength, leading to the need to have overdesigned elements. Around $80 \%$ of failures occurring in timber structures are caused by connection related issues (Itany and Faherty, 1984).

Dowel-type connections are among the most common connections in timber structures. The term dowel is broadly used for normal, self-drilling or tapping screws, nails, pins and dowels themselves.

Calculation of the load bearing capacity of dowel-type connectors subjected to shear, as example screwed connections, are based on Johansen's theory (Johansen, 1949). The model proposed by Johansen and its developments were the source for the EYM (European Yield Model), which is present in several standards and design codes, such as the present version of Eurocode 5 (EN 1995-1-1:2004) with the adaptations that have been done since it was first published. The EYM is an analysis model that allows to determine the load bearing capacity of dowel-type connections between two or three timber elements and is based on the stress equilibrium applied to the connector inserted in the timber element. It is a rather simple method, which provides better results for slim ductile connectors (Patton-Mallory et al. 1997), however it lacks a stringent mechanical basis (Dorn et al., 2013). Besides the geometrical 
characteristics of the connection, there are two essential parameters: the embedment strength of timber and the yielding moment of the fastener.

The validity of Johansen's theory has been verified several times, as instance in the experimental campaigns of Trayer (1932), McLain and Thangitham (1983) and Soltis et al. (1986), among others. According to it, the embedment strength of timber and the yielding moment of the fastener are the main parameters that govern the strength of dowel-type connections. Several studies have analyzed embedment strength of timber and of wood products.

Whale et al (1987) made an extensive work on the embedment strength of softwoods, hardwoods and plywood using nails and screws as connectors, while Ehlbeck and Werner (1992) studied the embedment strength of hardwoods under loading with different angles of application.

These two studies, that make part of the basis of Eurocode 5, only deal with the ultimate embedment strength, does not presenting any information regarding the elastic range. Kawamoto et al. (1993) experimentally analyzed the embedment strength on the direction perpendicular to the grain on glued laminated timber. Harada et al. (1999) and Hwang and Komatsu (1999) analyzed the relation between the dowel diameter and the embedment strength on glued laminated timber and wood products, respectively.

Sawata and Yasumura (2002) conducted a wide experimental campaign for the quantification of the embedment strength in both parallel and perpendicular to the grain directions. Recently, Santos et al. $(2009,2010)$ analyzed the embedment strength of Pinus pinaster in the parallel to the grain direction. In the study of Sandhaas et al. (2013), embedment tests parallel to the grain direction and ductility aspects using various species were analyzed and comparisons were made with the design equation from Eurocode 5. In that study it was found that the equations penalises species with higher density. 
Screwed connections, which are specially designed to transfer load in the axial direction, present an excellent solution for timber structures due to its easy application and higher withdrawal resistance. In the past years, several types of screws, with different shapes and materials, have been subject of interest by the scientific and technical communities. In Blass and Bejtka (2001), a comparison between results of connections with inclined screws and fasteners loaded perpendicular to their axis evidenced the opportunity of use for connections with inclined screws, especially concerning the rationalization and reduction of costs for timber-to-timber connections on design and installation. Moreover, in Bejtka and Blass (2002), a proposal for design rules for single-shear joints with inclined screws is presented, where it is possible to determine the load-carrying capacity for timber-to-timber connections with inclined screws taking into account the withdrawal and bending capacity of the screws, the timber embedding strength and the friction stress between the timber members. In that study, the withdrawal behaviour of the screws is taken into account in Johansen's extended yield theory using a modified withdrawal capacity parameter.

The load carrying capacity and base parameters for screwed connections is also discussed in Blass et al. (2006) and Pirnbacher et al. (2009) and the withdrawal capacity of self-tapping screws is further analyzed in Frese and Blass (2009), in Hübner (2013) for hardwoods and in Ringhofer et al. (2013) for unidirectional and layered timber products.

In Tomasi et al. (2010), an analysis was made to timber-to-timber joints (Picea abies Karst. glued laminated timber) connected with inclined screws, where the experimental values of strength and stiffness were compared with the theoretical ones obtained using Eurocode 5. On that study it was concluded that Eurocode 5 is partially unsuitable for describing the experimental results of strength and stiffness for those particular connector configurations. Comparison of the Eurocode 5 formulation with experiments on dowel-type connectors (on Norway spruce, Picea abies) has also been considered in Dorn et al. (2013), where for 
connections of intermediate slenderness, the theoretical formulation provided conservative design values for strength. Whereas, in some of the experiments, the design values overestimated the actual strengths considerably in connections of low, as well as of high, slenderness. These studies revealed the importance to test different connection systems and to compare the results with the theoretical formulation.

To that aim, this work analysis the use of two different wood species which until now have not been aim of thorough investigation. Actually, few are the studies that compare connection systems with self-tapping screws using European and African native woods, such as Maritime pine (the most important Portuguese wood species) and Iroko. The mechanical behaviour of the connections obtained experimentally will be compared with the formulation of Eurocode 5 (EN 1995-1-1:2004) including its adaptations.

With respect to Maritime pine, Machado and Cruz (2005) analyzed its mechanical properties accounting to the within stem variation, whereas in Branco et al. (2009), an experimental campaign was made considering laterally loaded nailed timber-to-timber connections for evaluation of the adequacy of Eurocode 5 formulation. In Santos et al. (2009), Maritime pine was experimentally analyzed to obtain data for implementation in an analytical model and for a three dimensional finite element model, whereas in Cruz (1996) a predictive model based on embedment properties was proposed considering the behaviour of structural timber joints of Maritime pine under cycling loading.

On the other hand, connections used with Iroko wood have even been less studied than those used with Maritime pine. As instance, the use of Iroko for carpentry and construction purposes has only been residual in some African countries (Ouinsavi et al. 2005; Adesogan, 2013), even if studies have been made to grade different types of native African species where Iroko was found to be suitable for structural purposes (Mvogo et al. 2011; Amoah et al. 2012). However, its use has been only considered in small elements, such as for studs 
between limecrete slabs and spruce glulam beams (Sebastian and Thompson, 2012). Therefore, this work also intends to provide information about the possible use of Iroko in a common structural connection system, comparing it to the use of Maritime pine timber.

\section{EXPERIMENTAL CAMPAIGN}

In this topic, the main steps of an extensive experimental campaign are presented with the objective of assessing the mechanical behaviour of self-tapping screw connections on two different wood species: Maritime pine and Iroko. Table 1 sums up the tests that were made.

Besides the connections themselves, the parameters that influence their load bearing capacity were also considered. Thus, embedment strength of timber in presence of metallic dowel and screw withdrawal tests for the three main directions (longitudinal, tangential and radial) of structural timber if approximated as continuum with linear elastic orthotropic properties, and different penetration depths were made, as well as the analysis on the headside pull-through strength.

\subsection{Materials}

The analyzed wood species are Maritime pine (Pinus pinaster Ait) and Iroko (Milícia excelsa). Maritime pine is usually graded as a C18 (EN 338:2009), however with a typical range of density of $500 \mathrm{~kg} / \mathrm{m}^{3}$ to $600 \mathrm{~kg} / \mathrm{m}^{3}$ at $12 \%$ moisture content (Silva et al. 2013). Pine corresponds to $62 \%$ of the gross value added of the Portuguese wood industry, where Maritime pine is the most important contributor being used in the cellulose industry but also in the construction market (e.g. used as solid timber and wood based panels such as OSB and MDF). On the other hand, Iroko is a highly valued commercial timber in Africa. It is used for both construction work and shipbuilding. It is used also for outdoor and indoor joinery, flooring and furniture. It presents a range of density of $550 \mathrm{~kg} / \mathrm{m}^{3}$ to $750 \mathrm{~kg} / \mathrm{m}^{3}$ at $12 \%$ 
moisture content. According to EN 1912:2004+A4:2010, Iroko is classified as D40. However, a mean value of $111 \mathrm{~N} / \mathrm{mm}^{2}$ for bending strength and $11.27 \mathrm{kN} / \mathrm{mm}^{2}$ for bending modulus of elasticity was documented by Tsoumis (1991) for this wood specie.

The Maritime pine came from Portuguese forests (Europe) whereas the Iroko timber came from the Republic of Congo (Africa). All the timber elements, after sawn, were placed in a climatic chamber with controlled temperature $\left(20^{\circ} \mathrm{C}\right)$ and air relative humidity $(65 \%)$ conditions for stabilization, until a $12 \%$ moisture content was reached for all samples.

The selected self-tapping screws were type HBS (Rotho Blaas), with nominal diameter of 6 $\mathrm{mm}$ and a shaft length of $160 \mathrm{~mm}$ (see Figure 1) which are in accordance with ETA-11/0030 (EOTA, 2012). These screws have a characteristic yield moment of $9493.7 \mathrm{Nmm}$ and a characteristic tension resistance of $11.3 \mathrm{kN}$. The shaft is partially threaded, consisting in a 75 mm length threaded zone from the tip of the screw followed by a transition zone of approximately $10 \mathrm{~mm}$ length, which decreases the torsion stress resistance and allows for an easier screwing process, and finally a non-threaded zone. The screw presents a countersunk head with a diameter of $12 \mathrm{~mm}$. The tip of the screw has a cut also to allow for an easier screwing process. A circular metallic dowel with diameter of $12 \mathrm{~mm}$, with S235 steel grade, was also used in this experimental campaign for the embedment strength tests of both timber species. The dowel was a STA12 with essential characteristics given in the declaration of performance STA12_CPR_20130701 (Rotho Blaas, 2013).

\subsection{Embedment strength of timber}

The embedment strength $\left(f_{\mathrm{h}}\right)$ of a given timber element is the average compressive stress at maximum load in the element under the action of a stiff linear fastener. The fastener's axis is perpendicular to the surface of the timber, while the loading direction is perpendicular to its axis. Its quantification may be made by two different methods, based on tests according to EN 
383:2007 and through the equations proposed on Eurocode 5. According to EN 383:2007, the specimen dimensions, type and location of the connector must be considered according preestablished relations with respect to the grain direction. The value of embedment strength $\left(f_{\mathrm{h}}\right)$ through that standard is given by:

$$
f_{\mathrm{h}}=\frac{F_{\max }}{d \cdot t}
$$

where $F_{\max }$ corresponds to the maximum load value obtained during the test $(\mathrm{N}), d$ is the connectors' diameter (mm) and $t$ is the thickness of the timber specimen (mm).

Considering the equations proposed on Eurocode 5 for the quantification of the characteristic embedment strength of a timber element $\left(f_{\mathrm{h}, \alpha, \mathrm{k}}\right)$, it is also needed to obtain the characteristic timber density $\left(\rho_{\mathrm{k}}\right)$, the connector diameter $(d)$ and the direction of the loading with respect to the grain $(\alpha)$, such as:

$$
f_{\mathrm{h}, \alpha, \mathrm{k}}=\frac{0.082 \cdot(1-0.01 \cdot d) \cdot \rho_{\mathrm{k}}}{k_{90} \cdot \sin ^{2} \alpha+\cos ^{2} \alpha}
$$

where $k_{90}$ is a factor depending on the material as:

$$
k_{90}= \begin{cases}1.35+0.015 \cdot d & \text { for softwoods } \\ 0.90+0.015 \cdot d & \text { for hardwoods }\end{cases}
$$

For this purpose, the density $(\rho)$ of each specimen, used in the experimental evaluation of $f_{\mathrm{h}}$, was quantified considering the methodology defined in ISO 13061-2:2014 and the characteristic value $\left(\rho_{\mathrm{k}}\right)$ of each sample was calculated by EN 384:2010. In order to consolidate the analytical evaluation and due to its influence on the mechanical performance of timber, also the moisture content $(w)$ was calculated through the method defined in ISO 13061-1:2014, and density was referred to a $12 \%$ moisture content. 
The equation provided in Eurocode 5 for the quantification of embedment strength of a timber element uses the characteristic density of the whole sample and it is not intended for use with the density of each specimen. Nevertheless, the pre-factor used in this equation (0.082) is maintained when using the mean values of density (Whale et al. 1987).

The evaluation of the embedment strength was differentiated regarding specimens tested in either parallel or perpendicular to the grain directions. The tests were made with displacement control accounting the procedure defined in EN 383:2007 with a displacement rate of $0.04 \mathrm{~mm} / \mathrm{s}$. Two transducers (LVDTs with $\pm 2.5 \mathrm{~mm}$ measuring range) were used to measure the displacement of the dowel while the timber element deformed.

Figure 2 gives the dimensions of the specimens used in the experimental evaluation of the embedment strength for both parallel and perpendicular to the grain directions, as well as the global setup for each of the cases.

\subsection{Screw withdrawal tests}

The screw withdrawal test was made according the indications provided by the standard EN 1382:2002. The objective of this test is to evaluate the withdrawal of the screw tip from a timber element, as illustrated in Figure 3. The connector is screwed in the timber specimen, with the dimensions established in the standard, with different penetration depths and angles. Loading is applied on the head of the connector as to extract it from the timber specimen. In the case of the longitudinal direction, four tests were made to each specimen respecting the spacing between measurements described in the standard. This was made to minimize the number of specimens and also to minimize the variability in the results due to the material.

The screws are inserted in the timber specimen without pre-drilling, on the longitudinal (L), radial $(\mathrm{R})$ and tangential $(\mathrm{T})$ to the grain directions, and the load needed for the withdrawal of 
the screw is taken for the depths of 8,10 and 12 times the nominal diameter of the screw (6 $\mathrm{mm}$ ), therefore for $48 \mathrm{~mm}, 60 \mathrm{~mm}$ and $72 \mathrm{~mm}$, respectively.

The load is applied by a metal grip designed specifically for screw withdrawal and a load rate of $0.2 \mathrm{kN} / \mathrm{s}$ was used in this experimental campaign. The specimen is placed behind metal plates that restrain it (Figure 4).

According to EN 1382:2002, the withdrawal parameter is given by:

$$
f_{\mathrm{ax}}=\frac{F_{\mathrm{ax}, \max }}{d \cdot l_{\mathrm{p}}}
$$

where $F_{\text {ax,max }}$ is the maximum withdrawal load obtained during the test $(\mathrm{N}), d$ is the nominal diameter of the connector $(\mathrm{mm})$ and $l_{\mathrm{p}}$ is the penetration depth of the threaded (or profiled) part of the screw (mm).

The equations regarding the withdrawal strength in Eurocode 5 are based in the model initially proposed in Blass et al. (2006) additionally including the number of screws $n$ of an axially loaded group of screws $\left(n_{\mathrm{ef}}=n^{0.9}\right.$ ) (Equation 5). For screws with nominal diameters between 6 and $8 \mathrm{~mm}$ the withdrawal capacity is reduced with the non-dimensional factor $\left(k_{\mathrm{d}}=\mathrm{d} / 8\right)$.

$$
R_{\mathrm{ax}, \mathrm{k}}=\frac{n_{e f} \cdot f_{a x, k} \cdot d \cdot l_{e f} \cdot k_{d}}{1.2 \cdot \cos ^{2} \alpha+\sin ^{2} \alpha}
$$

The withdrawal parameter $f_{\mathrm{ax}, \mathrm{k}}$ is calculated by:

$$
f_{a x, k}=0.52 \cdot d^{-0.5} \cdot l_{e f}^{-0.1} \cdot \rho_{k}^{0.8}
$$

Further in this work, this parameter was considered for comparison with the results of the withdrawal capacity obtained through EN 1382:2002. 


\subsection{Headside pull-through strength tests}

The headside pull-through is a possible failure mode of screwed connections, thus it is necessary to consider it on the quantification of the load-bearing capacity of these connections. In Eurocode 5, for axially loaded screws it is recommended that the headside pull-through capacity should be determined by tests, in accordance with EN 1383. In the case of EN1383:2002 the headside pull-through strength $\left(f_{\text {head }}\right)$ is given by

$$
f_{\text {head }}=\frac{F_{\text {head,max }}}{d_{\mathrm{h}}^{2}}
$$

where $F_{\text {head,max }}$ is the maximum pull-through load obtained during the test $(\mathrm{N})$ and $d_{\mathrm{h}}$ is the connector's head diameter (mm).

In this experimental campaign, a total of 46 tests were made of which 24 with Iroko timber and 22 with Maritime pine. During the tests, the screw was inserted in the center of one of the faces with largest area of the timber specimen, perpendicularly to that face (Figure 5). For each wood specie, half of the specimens had the screw positioned in the radial direction whereas the other half had the screw positioned in the tangential direction with respect to the annual growth rings. The specimen with the screw was then placed in a mechanism that restrained the displacement of the timber element. After, the tip of the screw was fixed to a metal grip and pulled until the head of the screw crossed all the timber specimen. A displacement rate of $0.3 \mathrm{~mm} / \mathrm{s}$ was considered for these tests.

\subsection{Simple shear tests of screwed connections}

After the withdrawal and headside pull-through tests, the connection system was also experimentally analyzed. The failure mechanisms associated to this test are the sum of all the parameters and respective failure modes, as well as the associated to the yield moment of the connector. 
The indications provided in Eurocode 5 for the case of screwed connections were followed for the definition of the geometry of the specimens (Figure 6).

The test procedure that was used is described in standard EN 26891:1991. Initially, a progressive compression loading is applied to the specimen, for 2 minutes, until $40 \%$ of the estimated load $\left(F_{\text {est }}\right)$ is reached. This load level is maintained for $30 \mathrm{~s}$, followed by a decrease of load down to $10 \%$ of $F_{\text {est }}$ and then the load is maintain for $30 \mathrm{~s}$. After that, a constant displacement rate is considered until the maximum load $\left(F_{\max }\right)$ is reached. It is important to notice that $F_{\max }$ corresponds to the maximum load obtained at a $15 \mathrm{~mm}$ relative displacement between the connected timber elements. In the case of failure of the connection before that relative displacement limit, the maximum load corresponds to the load at the moment of failure. The displacement rate is chosen so that the duration of the test is between 10 to 15 minutes. In this experimental campaign, a displacement rate of $0.06 \mathrm{~mm} / \mathrm{s}$ was considered.

\section{RESULTS}

In this section, the principal experimental results are summarized. Detailed results of the experimental campaigns are found at Ribeiro (2010) and Barros (2010).

\subsection{Embedment strength}

Table 2 provides the mean values of the main results for the embedment strength tests and the values proposed by Eurocode 5. Results are given regarding the density $(\rho)$, maximum load $\left(F_{\max }\right)$ and embedment strength $\left(f_{\mathrm{h}}\right)$ according to EN 383:2007 and Eurocode 5. For comparison purposes the values of the experimental campaign (namely density by specimen) were used in the calculations through Eurocode 5. The results are presented by direction relative to the grain $(\alpha)$ and wood species, in terms of mean value and coefficient of variation (CoV). In the case of the results obtained by EN 383:2007, the embedment strength was 
reached either when the maximum load was obtained or when deformation reached $5 \mathrm{~mm}$. Due to the different types of failure, the coefficient of variation of this parameter was higher than the density coefficient of variation for this sample. Higher coefficients of variation for the embedment strength compared to density were also present in Sandhaas et al. (2013). The correlation between the results obtained for the embedment strength obtained through EN 383:2007 and density are presented in Figure 7, for both wood species and direction relative to the grain. Higher determination coefficients are found for the parallel to the grain direction for both cases. Overall, the correlations tend to be stronger for lower values of $\mathrm{CoV}$ of the embedment strength obtained through EN 383:2007. Since the density is the only parameter with an assumed variability bigger than zero in Eurocode 5 equation, the determination coefficients between results of embedment strength obtained by the two different approaches are equal in value to the results presented in Figure 7.

\subsection{Screw withdrawal tests}

Table 3 gives the results for the screw withdrawal tests for the two selected wood species, in function of the grain direction. The results given are the mean value and coefficient of variation $(\mathrm{CoV})$ for the maximum load $\left(F_{\mathrm{ax}}\right)$, the characteristic value (5th percentile) $\left(F_{\mathrm{ax}, 05}\right)$ and the respective characteristic withdrawal capacity $\left(f_{\text {ax }, 05}\right)$. Characteristic density is also provided in Table 3 per each sample. Due to the rather small sample size, the characteristic density was obtained by statistical ranking of the density values referred to a $12 \%$ moisture content. Since the sample size too small to obtain a stable coefficient of variation and considering that the longitudinal direction tests were made within the same specimen, the coefficient of variation was not measured for that case. The characteristic value of the maximum load was obtained both by rank statistics and according to EN 14358:2006 and it was found that only for the longitudinal in Iroko significant differences are obtained. On the 
other cases a mean difference of approximately $5 \%$ or less is found for each direction. The characteristic withdrawal capacity was obtained regarding the characteristic values obtained by ranking statistics due to the small size sample and regarding small differences with the values of EN 14358:2006.

Attending to the relation between density and withdrawal parameter obtained through 1382:2002, it was found that overall a weak correlation is obtained $\left(r^{2}\right.$ below 0.10$)$ for both species and directions.

An important observation is that for both Iroko and Maritime pine, when the penetration depth was of $72 \mathrm{~mm}$, failure occurred always by the screw and not by the wood. Since failure was obtained by reaching the tensile capacity of the screw, these tests were not considered in further analysis as they do not represent the withdrawal parameter. For the remaining depths, failure occurred in the wood for either species.

As it was expected, the load necessary to withdraw the screw from the timber element increased with higher depths of penetration, regardless of the wood species.

According to Wilcoxon-Mann-Whitney statistical tests, there is no significant difference (at a significance level of 5\%) between the experimental results for maximum withdrawal load when the screw is either inserted in the tangential or radial direction (mean difference of $6.4 \%$ and $2.1 \%$ for Maritime pine and Iroko, respectively). However, when the screw is inserted parallel to the grain direction (longitudinal), a considerable decrease of the withdrawal load is visible (mean decrease of $10.2 \%$ and $8.4 \%$ for Maritime pine and Iroko, respectively).

Also, according to Wilcoxon-Mann-Whitney statistical tests there is no significant difference (at a significance level of 5\%) between species. The mean difference on maximum withdrawal load for the two species is less than $10 \%$ on all three directions $(9.4 \%, 4.6 \%$ and $0.3 \%$ for tangential, radial and longitudinal directions, respectively), while the values of coefficient of variation were slightly lower the case of Iroko wood. Concluding, in Figures 8 
and 9 the averaged curves of load-displacement relation are presented (displacement is measured globally corresponding to the total test assembly displacement), considering the two wood species, the three analyzed directions and the three studied penetration depths. On those figures it is found that higher penetration tests evidence higher withdrawal loads for all cases. For the higher penetration depths (12d), since failure was controlled by the tensile capacity of the screw, a more pronounced peak and decrease of load capacity is seen for the average curves. This was more visible for the case of Iroko, whereas for Maritime pine the post peak behaviour presents a less pronounced decrease. In the case of Iroko, it should also be noted that failure was obtained in a rather specific interval of displacement regardless of the penetration depth.

\subsection{Headside pull-through strength tests}

Table 4 gives the results for the headside pull-through strength for Iroko and Maritime pine wood, evidencing the mean value and $\mathrm{CoV}$ for the mean maximum load $\left(F_{\text {head }}\right)$ and characteristic value (5th percentile) $\left(F_{\text {head,05 }}\right)$, as well as the mean headside pull-through strength $\left(f_{\text {head }}\right)$.

During the headside pull-through tests a mean value of strength capacity for Iroko of 38.6 MPa was found, while a mean value of $40.4 \mathrm{MPa}$ for the same parameter was obtained for the Maritime pine (4.6\% difference). For this case, the results for both species were found in a similar range (considering a Wilcoxon-Mann-Whitney there was no significant difference at a significance level of 5\%), however it was found that the correlation of density and headside pull-through strength, for this experimental campaign, was stronger for Iroko than for Maritime pine, as presented in Figure 10. 
In Figure 11 the averaged curves of load-displacement relation for the headside pull-through tests are presented, considering the two wood species. The curve represents the average of load of each test on a given level of displacement. On those curves, Maritime pine presents a higher initial mean stiffness with a less ductile pos-peak behaviour, whereas Iroko evidences a higher ductile branch after failure. It must be noted that, although Iroko presents a higher peak for a specific interval of displacement (around $28 \mathrm{~mm}$ ), the underlying results have a larger dispersion compared to those of Maritime pine.

\subsection{Simple shear tests of screwed connections}

Table 5 gives the results for the simple shear tests of screwed connections for the two selected wood species. The results given are the mean value $(F)$ and coefficient of variation $(\mathrm{CoV})$ for the maximum load $\left(F_{\max }\right)$, the estimated maximum load $\left(F_{\text {est }}\right)$ and the characteristic value for the 5th percentile $\left(F_{05}\right)$. The mean value of slip modulus, calculated through EN 26891:1991, is also presented. A total of 20 connections were tested with Maritime pine, while 21 connections were tested with Iroko.

The results obtained for the two wood species are statistically different regarding a WilcoxonMann-Whitney test (significance level of 5\%) with a mean increase of $8.5 \%$ for the maximum load for connections with Iroko (Figure 12). The results of connections with Iroko timber are less variable than those with Maritime pine.

\section{DISCUSSION OF RESULTS}

This work allowed for the comparison of the embedment strength obtained through Eurocode $5\left(f_{\mathrm{h}, \mathrm{EC} 5}\right)$ with experimental results made following the standard EN 383:2007 $\left(f_{\mathrm{h}, \mathrm{EXP}}\right)$. In Figure 13, the comparison between the two approaches taking as reference benchmark the values obtained through EN 383:2007. From that analysis, it was found that on the majority of 
cases, the results obtained experimentally are higher than those obtained via Eurocode 5, making the use of those expressions a conservative approach suitable for structural safety design of these connections. The exception was the results for Iroko embedment strength in the perpendicular to the grain direction.

With respect to the screw withdrawal tests, the comparison between results obtained through both approaches is presented in Figure 14, where it is visible that the Eurocode 5 approach underestimates the withdrawal capacity compared to the experimental results, except for Iroko on the longitudinal direction.

The results of the headside pull-through tests evidenced a $5 \%$ percentile for maximum applied load of $5.00 \mathrm{kN}$ and of $4.25 \mathrm{kN}$, respectively for Maritime pine and Iroko. These values are lower than the results obtained in the withdrawal tests in terms of applied load, however the respective strength is higher since it represents a strength mechanism localized in the head of the screw, while for withdrawal the strength mechanism is formed along the entire penetration length.

Considering Eurocode 5, the results of the prior tests were used to predict the simple shear test results. Initially, only the information from the embedment strength tests was used and, assuming the same density as obtained on those tests, resulted in a load capacity of $6.12 \mathrm{kN}$ and $6.11 \mathrm{kN}$ for Maritime pine and Iroko, respectively. However, if the contribution of the rope effect is added by considering the withdrawal capacity obtained in the prior tests, the values would increase to $11.0 \mathrm{kN}$ and $10.5 \mathrm{kN}$ for Maritime pine and Iroko, respectively. In the experimental tests the results for the $5 \%$ percentile were of $8.62 \mathrm{kN}$ and $9.56 \mathrm{kN}$ for Maritime pine and Iroko, respectively. The presented results confirm the reliability of the Eurocode 5 method for these screwed connections for both wood species, being conservative if not considering the rope effect but providing higher values if the rope effect is considered. 
According to Eurocode 5, in the case of screws with slenderness of $16 d$, failure occurs by crushing of the two timber elements and by bending of the screw, that is by failure mode (f) described in that code (see EN 1995-1-1:2004, section 8.2). The failure modes occurred during the experimental campaign were assessed by cutting the specimens and observing the behavior of the connection (Figure 15). It was concluded that the failure occurred by local crushing of timber near the connection and by bending of the screw, as predicted by Eurocode 5.

\section{CONCLUSIONS}

On this work, an experimental campaign was made to assess the mechanical behaviour of a connection system considering self-tapping screws on Maritime pine and Iroko wood species. From this work it is concluded that comparing the embedment strength obtained by Eurocode 5 and the one obtained experimentally through EN 383:2007, in the majority of cases, the experimental values are higher. Also, regarding the comparison between the two species, Iroko presents higher embedment strength for parallel to the grain direction while for the perpendicular direction only a slight difference is present.

In terms of screw withdrawal load, it was experimentally found that the results obtained for the perpendicular to the grain direction (tangential and radial) were higher compared to the results for the parallel to the grain direction (longitudinal) (mean decrease of $13.9 \%$ and $8.0 \%$ for Maritime pine and Iroko, respectively).

Although similar results were obtained for both wood species, Maritime pine presented higher values of screw withdrawal and headside pull-through strengths, whereas Iroko evidenced higher results for embedment strength. In the simple shear tests of the screwed connection system, connections with Iroko presented a higher load-bearing capacity and lower variability compared to the performance of Maritime pine connections, being the results statistically 
different according to Wilcoxon-Mann-Whitney tests. Overall, the experimental results for the simple shear screwed connections were slightly higher than the predicted by the Eurocode 5 formulation.

This work evidenced that both Maritime pine and Iroko presented similar mechanical performance for the analyzed self-tapping screwed connections and that they are able to comply with the requirements from Eurocode 5.

\section{ACKNOWLEDGEMENTS}

The authors acknowledge the support of Rotho Blaas (offer of self-tapping screws) and of the Structural Lab from University of Minho (test facilities). This work was supported by FCT (Portuguese Foundation for Science and Technology), within ISISE, project UID/ECI/04029/2013.

\section{REFERENCES}

Adesogan S. O. (2013). Wooden materials in building projects: Fitness for roof construction in southwestern Nigeria. Journal of Civil Engineering Construction Technology, $4(7), 217-223$

Amoah M., Appiah-Yeboahand J., Okai R. (2012). Characterization of physical and mechanical properties of branch: Stem and root wood of iroko and emire tropical trees. Research Journal of Applied Sciences, Engineering and Technology, 4(12), $1755-1761$.

Barros B.M.V. (2010). Avaliação experimental de ligações coladas e aparafusadas em estruturas de madeira, Masters dissertation in Civil Engineering, University of Minho (in Portuguese). 
Bejtka I., Blass H.J. (2002). Joints with inclined screws. In: Proccedings of the 35th CIB W18 Meeting.

Blass H.J., Bejtka I. (2001). Screws with continuous threads in timber connections, In: S. Aicher, ed., 'Joints in timber structures. Proceedings of the International RILEM Symposium, Stuttgart, Germany', number 22 in 'RILEM publications', pp. 193201.

Blass H.J., Bejtka I., Uibel T. (2006). Tragfähigkeit von Verbindungen mit selbstbohrenden Holzschrauben mit Vollgewinde, Band 4 in 'Karlsruher Berichte zum Ingenieurholzbau', Universitätsverlag Karlsruhe. (in German).

Branco J. M., Cruz P. J., Piazza M. (2009). Experimental analysis of laterally loaded nailed timber-to-concrete connections. Construction and Building Materials, 23(1), 400410.

Cruz H. (1996). Behavior of structural timber joints under cyclic loading. Predictive modeling based on embedment properties. In: Proceedings of the International Wood Engineering Conference, ICWE, New Orleans, USA.

Dorn M., de Borst K., Eberhardsteiner J. (2013). Experiments on dowel-type timber connections. Engineering Structures, 47, 67-80.

Ehlbeck J., Werner H. (1992). Softwood and hardwood embedding strength for dowel-type fasteners. In: Proceedings of the CIB-W18 meetings, pp 25-7-2.

Frese M., Blass H.J. (2009). Models for the calculation of the withdrawal capacity of selftapping screws. In: Proceedings of the 42nd CIB W18 Meeting.

EN 14358:2006, Timber structures - Calculation of characteristic 5-percentile values and acceptance criteria for a sample. European Committee for Standardization.

EN 1995-1-1:2004, Eurocode 5: Design of Timber Structures - Part 1-1: General- Common rules and rules for buildings. European Committee for Standardization. 
EN 1912:2004+A4:2010, Structural timber - Strength classes - Assignment of visual grades and species. European Committee for Standardization.

EN 338:2009, Structural timber - Strength classes. European Committee for Standardization.

EN 383:2007, Timber structures - Test methods - Determination of embedding strength and foundation values for dowel type fasteners. European Committee for Standardization.

EN 384:2010, Structural timber - Determination of characteristic values of mechanical properties and density. European Committee for Standardization.

EOTA (2012). European Technical Approval ETA-11/0030: Rotho Blaas Self-tapping screws. European Organisation for Technical Approvals.

Harada M., Hayashi T., Karube M., Komatsu K. (1999). Dowel-bearing test of glued laminated timber with a drift-pin (in Japanese). Summary of technical paper, annual meeting, Architectural institute of Japan, pp 49-50.

Hübner U. (2013). Withdrawal strength of self-tapping screws in hardwoods. In: Proceedings of the 46th CIB W18 Meeting.

Hwang K.H., Komatsu K. (1999). Relationship between embedment parameters and dowel diameter for various engineered woods (EW) (in Japanese). Summary of technical paper of annual meeting, Architectural Institute of Japan, pp 51-52.

ISO 13061-1:2014. Physical and mechanical properties of wood - Test methods for small clear wood specimens - Part 1: Determination of moisture content for physical and mechanical tests, International Organization for Standardization.

ISO 13061-2:2014. Physical and mechanical properties of wood - Test methods for small clear wood specimens - Part 2: Determination of density for physical and mechanical tests, International Organization for Standardization. 
Itany R.Y., Faherty K.F. (1984). Structural wood research, state-of-the-art and research needs. NY: ASCE.

Johansen K.W. (1949). Theory of Timber Connections. In International Association of Bridge and Structural Engineering.

Kawamoto N., Komatsu K., Harada M. (1993). Lateral strengths of drift-pin joints in perpendicular to the grain loadings. III Estimation of yield loads by European yield theory (in Japanese). Mokuzai Gakkaishi 39:1386-1392.

Machado J.S., Cruz H.P. (2005). Within stem variation of Maritime Pine timber mechanichal properties. Holz als Roh-und Werkstoff, 63(2), 154-159.

McLain T.E., Thangjitham S. (1983). Bolted wood-joint yield model. Journal of Structural Division, ASCE, 109(8): 1820-1835.

Mvogo J.K., Ohandja L.A., Minsili L.S., Castera P. (2011). Mechanical grading of structural timber and species conservation in the forest of the Congo Basin. African Journal of Environmental Science and Technology, 5(2), 111-125.

Ouinsavi C., Sokpon N., Bada O. (2005). Utilization and traditional strategies of in situ conservation of iroko (Milicia excelsa Welw. CC Berg) in Benin. Forest Ecology and Management, 207(3), 341-350.

Patton-Mallory M., Pellicane P.J., Smith F.W. (1997). Modeling bolted connections in wood: review. Journal of Structural Engineering, 123(8), 1054-1062.

Pirnbacher G., Brandner R., Schickhofer G. (2009). Base parameters of self-tapping screws. In: Proceedings of the 42nd CIB W18 Meeting.

Ribeiro N.H.P. (2010), Avaliação experimental do esmagamento localizado da madeira. Dissertation on the Masters of Sustainable Construction and Rehabilitation, University of Minho (in Portuguese). 
Rotho Blaas (2013). Declaration of performance STA_12_CPR_20130701. Cortaccia, Italy.

Ringhofer A., Brandner R., Schickhofer G. (2015). Withdrawal resistance of self-tapping screws in unidirectional and orthogonal layered timber products. Materials and Structures, 48(5), 1435-1447. doi: 10.1617/s11527-013-0244-9.

Sandhaas C., Ravenshorst G.J.P., Blass H. J., van de Kuilen J.W.G. (2013). Embedment tests parallel-to-grain and ductility aspects using various wood species. European Journal of Wood and Wood Products, 71(5), 599-608 doi: 10.1007/s00107-0130718-z.

Santos C.L., De Jesus A.M.P., Morais J.J.L., Lousada J.L.P.C. (2009). Quasi-static mechanical behaviour of a double-shear single dowel wood connection. Construction and Building Materials, 23(1), 171-182.

Santos C.L., De Jesus, A.M.P., Morais J.J.L., Lousada J.L.P.C. (2010). A Comparison Between the EN 383 and ASTM D5764 Test Methods for Dowel Bearing Strength Assessment of Wood: Experimental and Numerical Investigations. Strain, 46(2), 159-174.

Sawata K., Yasumura M. (2002). Determination of embedding strength of wood for doweltype fasteners. Journal of Wood Science, 48(2), 138-146.

Sebastian W., Thompson S. (2012). Indicative comparisons between bonded and dowelled hardwood studs for limecrete-spruce connections under load-unload-reload double-shear testing. Engineering Structures, 45, 151-165.

Silva M.E., Dias A., Lousada J.L. (2013). Madeira de Pinho - caraterísticas e utilização. ed. 1, vol. 1, ISBN: 978-989-704-116-7. Vila Real: UTAD. (in Portuguese).

Soltis L.A., Hubard F.K., Wilkinson T.L. (1986). Bearing strength of bolted timber joints. Journal of Structural Engineering, ASCE, 112(9): 2141-2154. 
Tomasi R., Crosatti A., Piazza M. (2010). Theoretical and experimental analysis of timber-totimber joints connected with inclined screws. Construction and Building Materials, 24(9), 1560-1571.

Trayer G.W. (1932). The bearing strength of wood under bolts, Technical Bulletin No. 332, USDA Washington DC.

Tsoumis G. (1991). Science and technology of wood. Structure, properties, utilization. Van Nostrand Reinhold.

UNI EN 1382:2002, Strutture di legno - Metodi di prova - Resistenza all'estrazione di elementi meccanici di collegamento per legno. UNI.

UNI EN 1383:2002, Strutture di legno - Metodi di prova - Resistenza all'attraversamento della testa di elementi meccanici di collegamento per legno. UNI

UNI EN 26891:1991, Legno, strutture di legno. Assemblaggi realizzati tramite elementi meccanici di collegamento. Principi generali perl a determinazione delle caractteristiche di resitenza e deformabilita. UNI.

Whale L.R.J., Smith I., Larsen H.J. (1987). Design of nailed and bolted joints proposals for the revision of existing formulae in draft Eurocode 5 and the CIB code. In: Proceedings of the CIB-W18 meetings, Paper 20-7-1. 
TABLES

Table 1 - Experimental campaign

\begin{tabular}{|c|c|c|c|c|}
\hline \multicolumn{3}{|c|}{ Test } & \multicolumn{2}{|c|}{ Number of tests } \\
\hline \multirow{3}{*}{$\begin{array}{l}\text { Embedment strength } \\
\qquad \text { EN 383:2007 } \\
\text { (with metallic dowel) }\end{array}$} & \multicolumn{2}{|c|}{ Direction } & Maritime pine & Iroko \\
\hline & \multicolumn{2}{|c|}{ Parallel to the grain } & 49 & 49 \\
\hline & \multicolumn{2}{|c|}{ Perpendicular to the grain } & 49 & 49 \\
\hline \multirow{10}{*}{$\begin{array}{l}\text { Screw withdrawal } \\
\text { UNI EN 1382:2002 }\end{array}$} & Direction & Penetration & & \\
\hline & \multirow{3}{*}{ Tangential } & $8 \mathrm{~d}$ & 7 & 7 \\
\hline & & $10 \mathrm{~d}$ & 7 & 7 \\
\hline & & $12 \mathrm{~d}$ & 4 & 5 \\
\hline & \multirow{3}{*}{ Radial } & $8 \mathrm{~d}$ & 7 & 7 \\
\hline & & $10 \mathrm{~d}$ & 7 & 7 \\
\hline & & $12 \mathrm{~d}$ & 2 & 5 \\
\hline & \multirow{3}{*}{ Parallel } & $8 \mathrm{~d}$ & 8 & 8 \\
\hline & & $10 \mathrm{~d}$ & 4 & 4 \\
\hline & & $12 \mathrm{~d}$ & 4 & 4 \\
\hline \multicolumn{3}{|c|}{ Screw headside pull-through UNI EN 1383:2002 } & 22 & 24 \\
\hline \multicolumn{3}{|c|}{ Simple shear of screwed connections UNI EN 26891:2001 } & 20 & 21 \\
\hline
\end{tabular}

Table 2 - Embedment strength of the evaluated wood species.

\begin{tabular}{|c|c|c|c|c|c|c|c|}
\hline \multirow{2}{*}{ Species } & \multirow{2}{*}{$\alpha$} & \multirow{2}{*}{$\begin{array}{c}\rho \\
\left(\mathrm{kg} / \mathrm{m}^{3}\right)\end{array}$} & \multirow{2}{*}{$\begin{array}{l}\mathrm{CoV} \\
(\%)\end{array}$} & \multirow{2}{*}{$\begin{array}{l}F_{\max } \\
(\mathrm{kN})\end{array}$} & \multicolumn{2}{|c|}{ EN 383:2007 } & Eurocode 5 \\
\hline & & & & & $f_{\mathrm{h}}(\mathrm{MPa})$ & $\mathrm{CoV}(\%)$ & $f_{\mathrm{h}}(\mathrm{MPa})$ \\
\hline \multirow{2}{*}{$\begin{array}{c}\text { Maritime } \\
\text { pine }\end{array}$} & $0^{\circ}$ & 664 & 8.1 & 23.1 & 48.2 & 10.9 & 48.0 \\
\hline & $90^{\circ}$ & 686 & 4.7 & 18.5 & 38.4 & 15.3 & 32.4 \\
\hline \multirow{2}{*}{ Iroko } & $0^{\circ}$ & 607 & 7.9 & 24.2 & 50.4 & 14.0 & 43.8 \\
\hline & $90^{\circ}$ & 659 & 7.2 & 18.2 & 37.9 & 13.2 & 44.0 \\
\hline
\end{tabular}


Table 3 - Withdrawal test results.

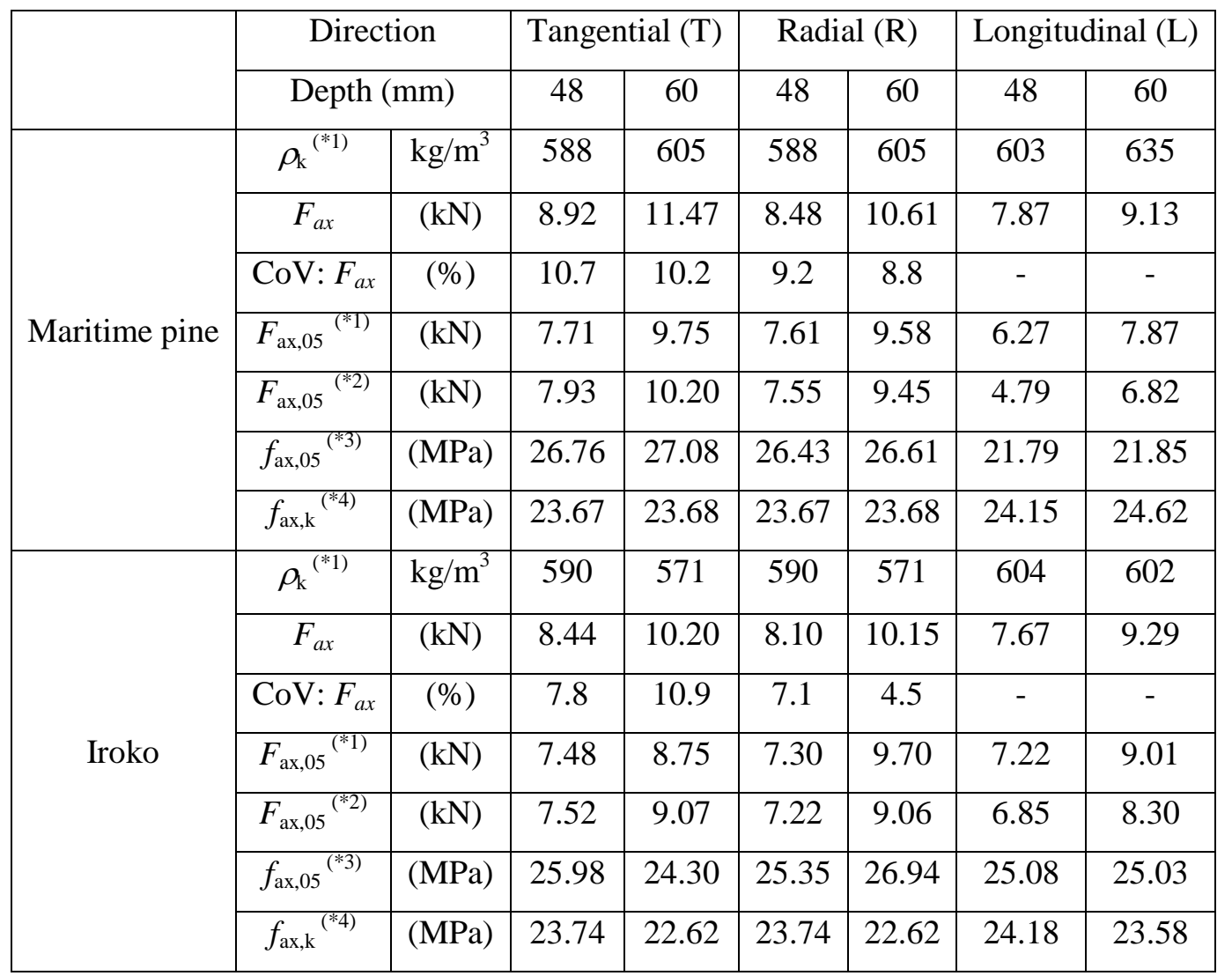

${ }^{(* 1)}$ characteristic value obtained through rank statistics

${ }^{\left({ }^{* 2}\right)}$ characteristic value obtained through EN 14358

${ }^{(* 3)}$ calculated through EN 1382:2002

${ }^{(* 4)}$ calculated through Eurocode 5

Table 4 - Results of the headside pull-through tests.

\begin{tabular}{|c|c|c|c|c|c|c|c|c|}
\hline \multirow{3}{*}{ Species } & \multicolumn{4}{|c|}{$F_{\text {head }}$} & \multicolumn{4}{|c|}{$f_{\text {head }}$} \\
\hline & \multirow{2}{*}{$\begin{array}{c}\text { mean } \\
(\mathrm{kN})\end{array}$} & \multirow{2}{*}{$\operatorname{CoV}(\%)$} & \multicolumn{2}{|c|}{$F_{\text {head,05 }}(\mathrm{kN})$} & \multirow{2}{*}{ mean $(\mathrm{MPa})$} & \multirow{2}{*}{$\mathrm{CoV}(\%)$} & \multicolumn{2}{|c|}{$f_{\text {head }, 05}(\mathrm{MPa})$} \\
\hline & & & $(* 1)$ & $(* 2)$ & & & $(* 1)$ & $(* 2)$ \\
\hline Maritime pine & 5.81 & 10.8 & 5.00 & 4.52 & 40.4 & 10.8 & 34.7 & 35.9 \\
\hline Iroko & 5.56 & 18.1 & 4.25 & 3.62 & 38.6 & 18.1 & 29.5 & 25.1 \\
\hline
\end{tabular}

${ }^{(* 1)}$ characteristic value obtained through rank statistics

${ }^{(* 2)}$ characteristic value obtained through EN 14358 
Table 5 - Results of the simple shear tests of screwed connections.

\begin{tabular}{|c|c|c|}
\hline & Maritime pine & Iroko \\
\hline$F_{\text {est }}(\mathrm{kN})$ & 10.00 & 12.00 \\
\hline$F(\mathrm{kN})$ & 10.05 & 10.90 \\
\hline $\mathrm{CoV}(\%)$ & 10.1 & 9.7 \\
\hline$F_{05}(\mathrm{kN})^{(* 1)}$ & 8.62 & 9.56 \\
\hline$F_{05}(\mathrm{kN})^{(* 2)}$ & 9.48 & 9.50 \\
\hline$k_{\mathrm{s}}(\mathrm{kN} / \mathrm{mm})$ & 2.89 & 2.91 \\
\hline
\end{tabular}

${ }^{(* 1)}$ characteristic value obtained through rank statistics

${ }^{(* 2)}$ characteristic value obtained through EN 14358 


\section{FIGURES}

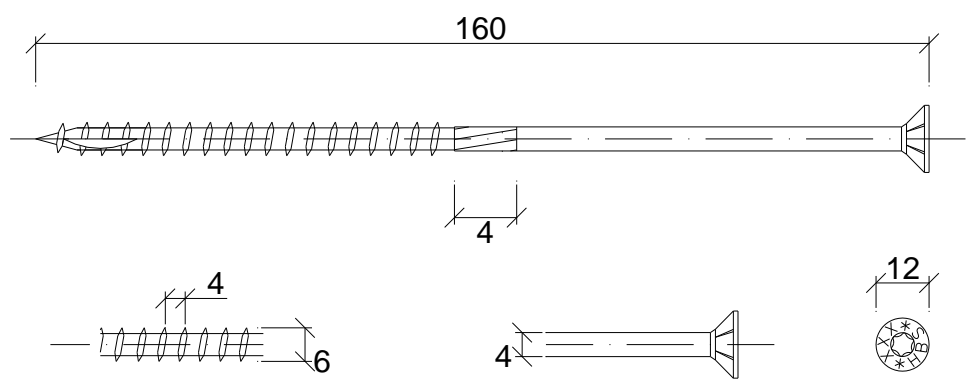

Figure 1: HBS 6x160 geometry (mm).
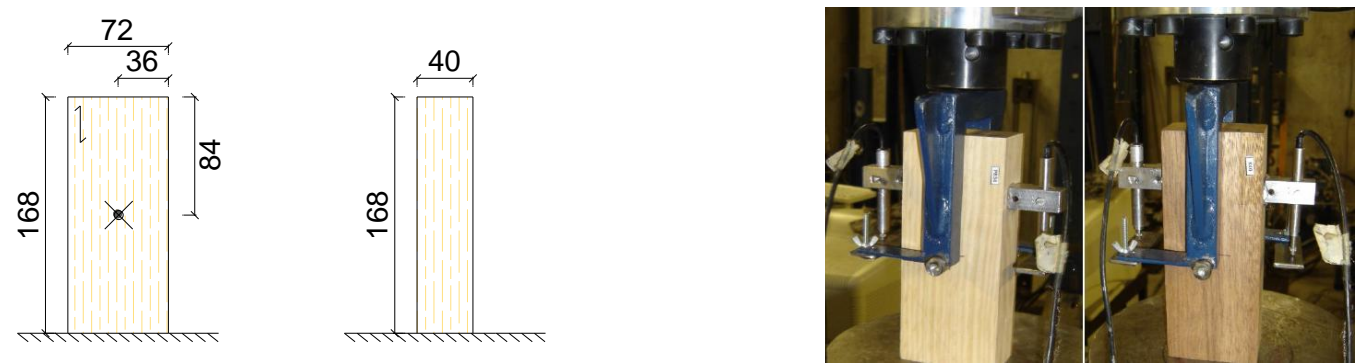

a)
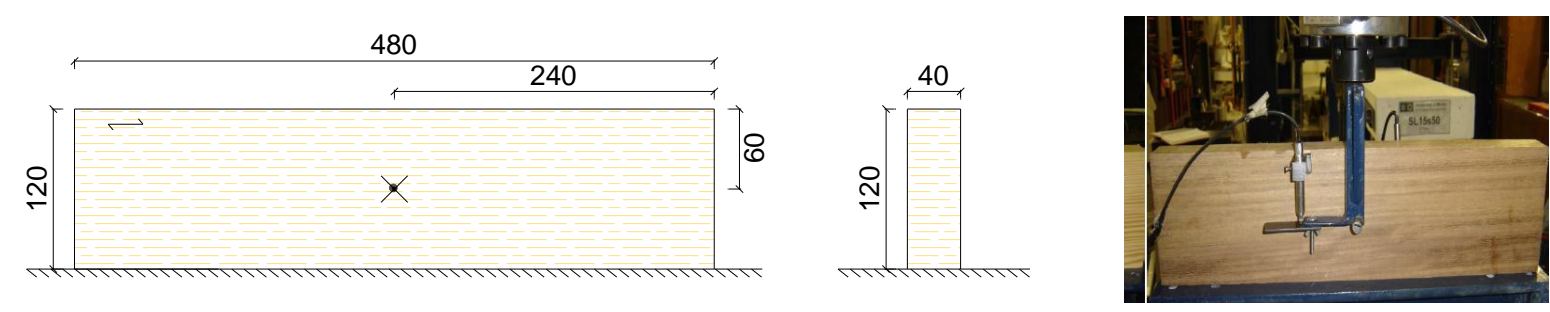

b)

Figure 2: Geometry of specimens and test setup (dimensions in $\mathrm{mm}$ ): a) parallel to the grain direction; b) perpendicular to the grain direction. 


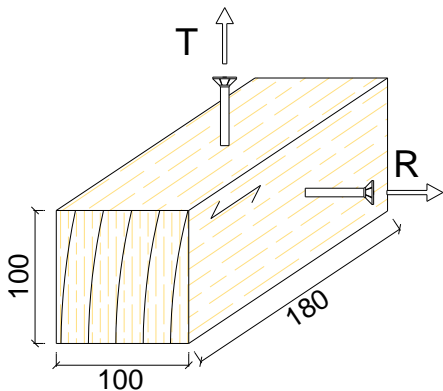

a)

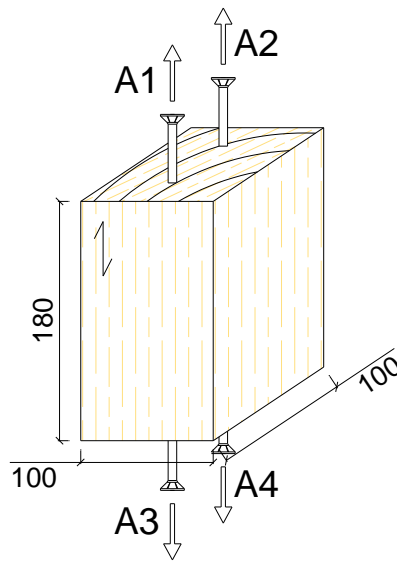

b)

Figure 3: Geometry for withdrawal tests (dimensions in $\mathrm{mm}$ ) for: a) tangential (T) and radial (R) directions; b) longitudinal (L) direction.

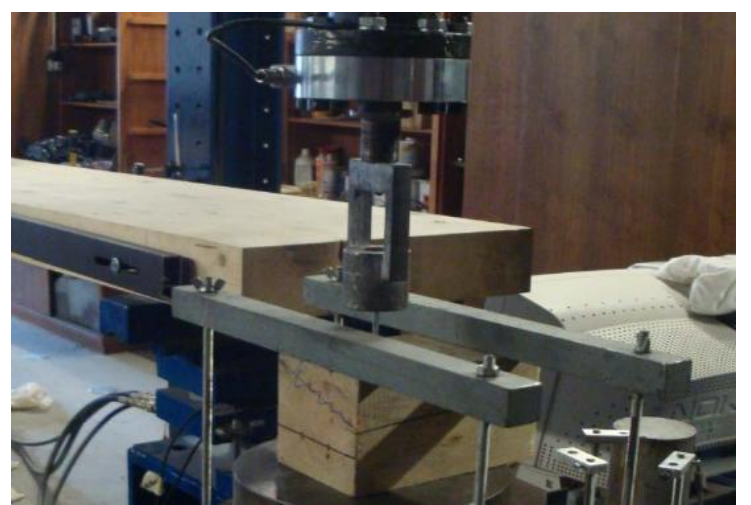

Figure 4: Setup used in laboratory for the withdrawal tests. 


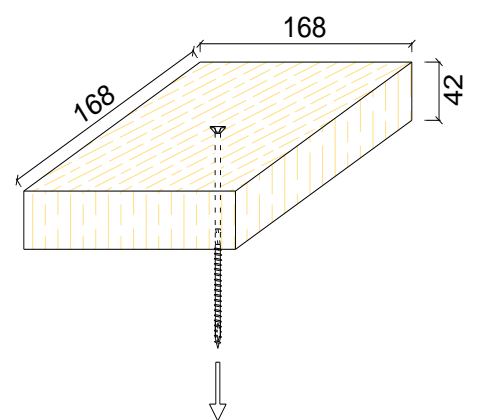

Figure 5: Geometry used for the headside pull-through tests (dimensions in $\mathrm{mm}$ ).

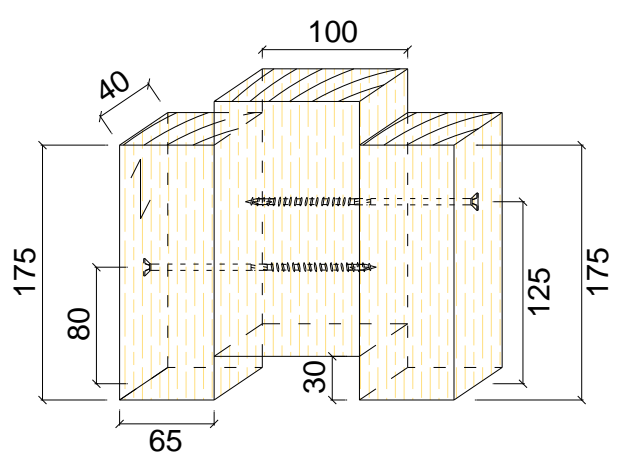

a)

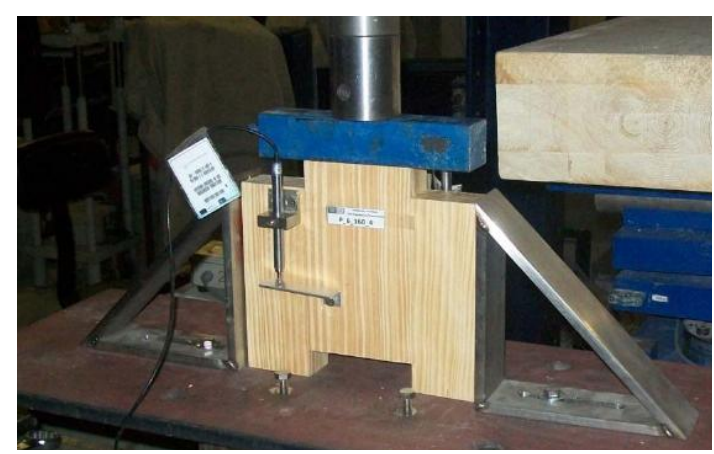

b)

Figure 6: Setup for the simple shear tests: a) specimen's geometry (dimensions in mm); b) setup with data acquisition system. 


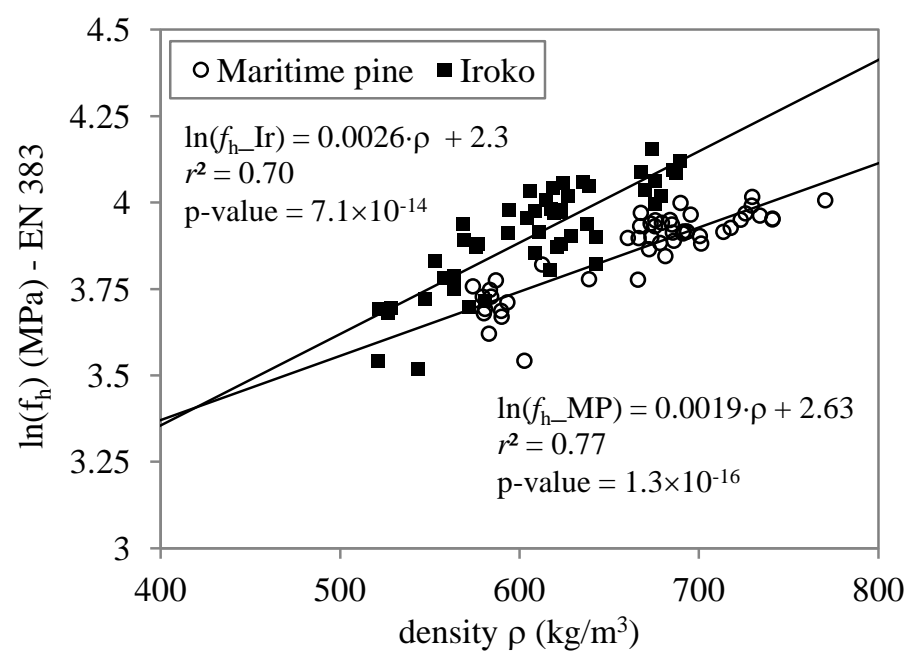

a)

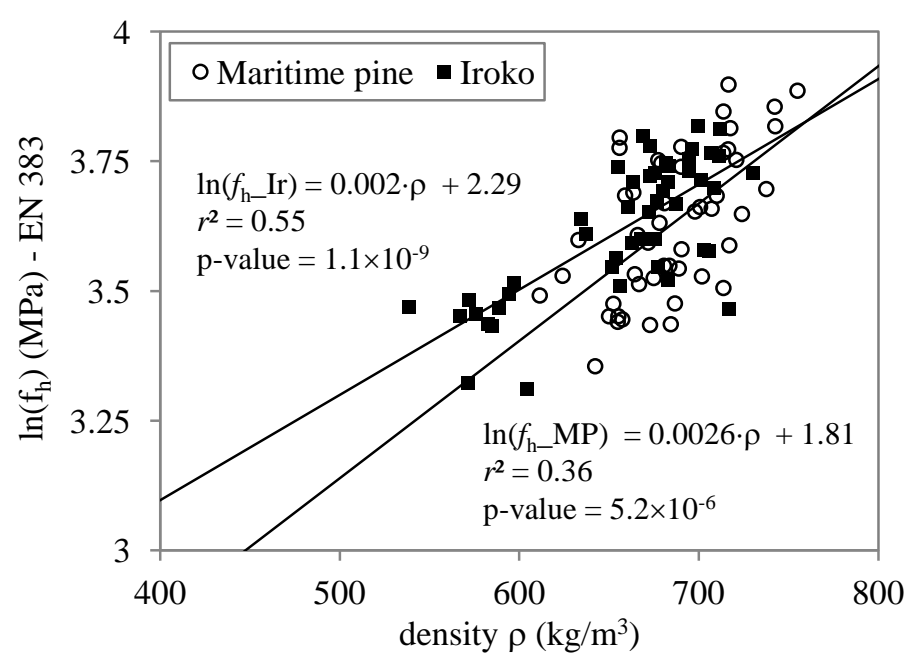

b)

Figure 7: Correlation between embedment strength (obtained through EN 383:2007) and density: a) in parallel to the grain direction; b) in perpendicular to the grain direction. 


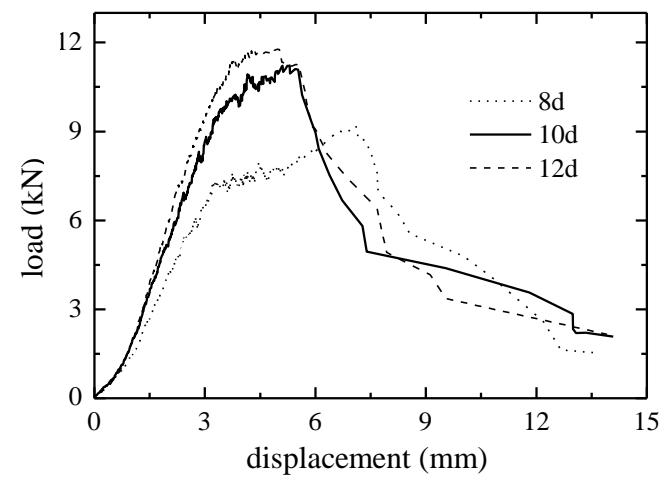

a)

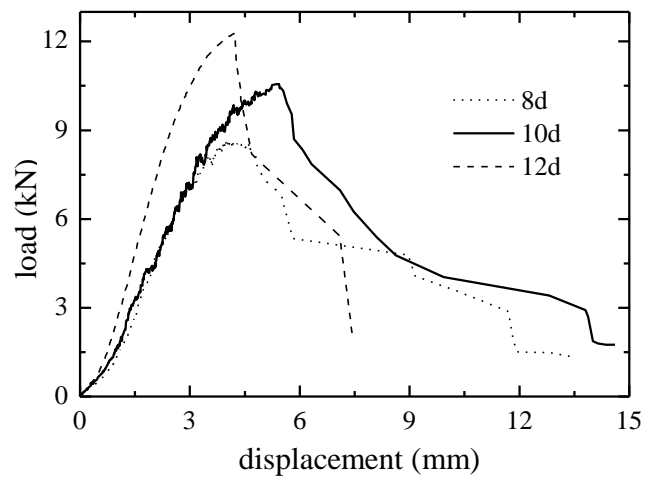

b)

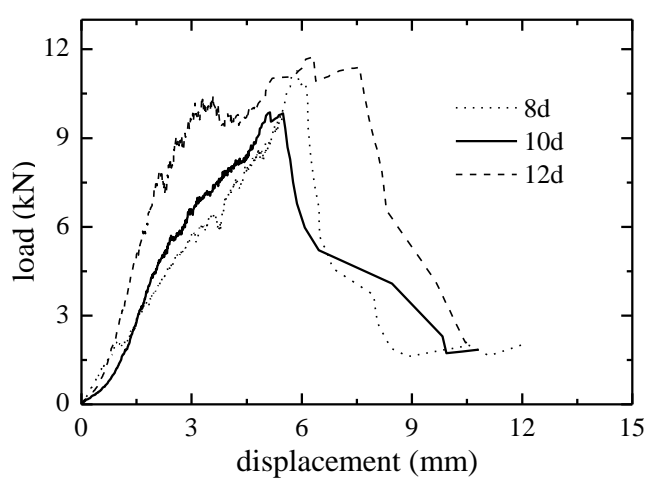

c)

Figure 8: Averaged load-displacement curves for withdrawal tests in Maritime pine: a) tangential direction; b) radial direction; c) longitudinal direction. 


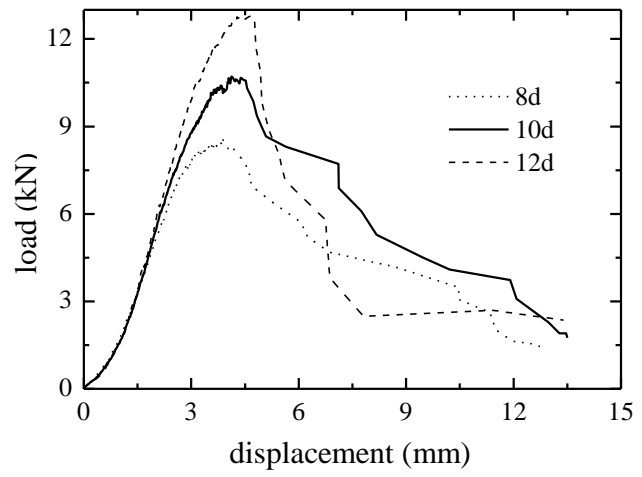

a)

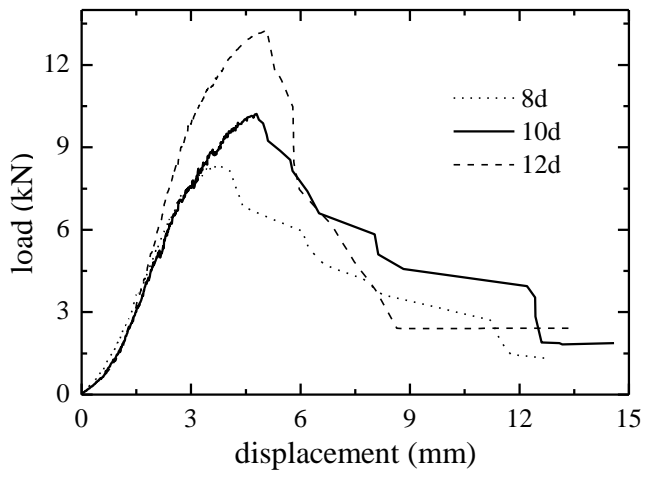

b)

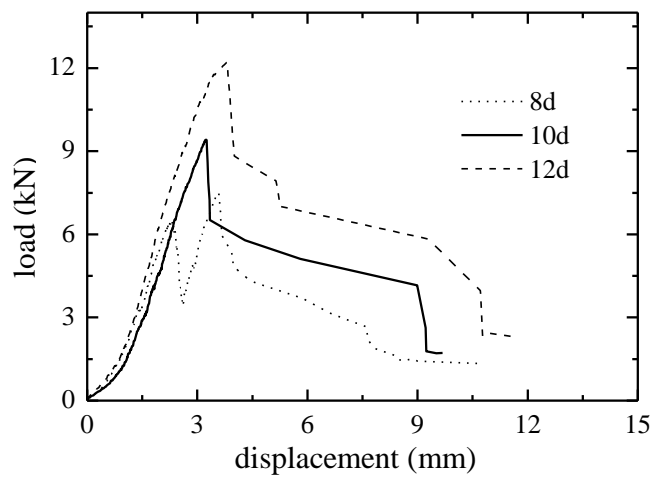

c)

Figure 9: Averaged load-displacement curves for withdrawal tests in Iroko: a) tangential direction; b) radial direction; c) longitudinal direction.

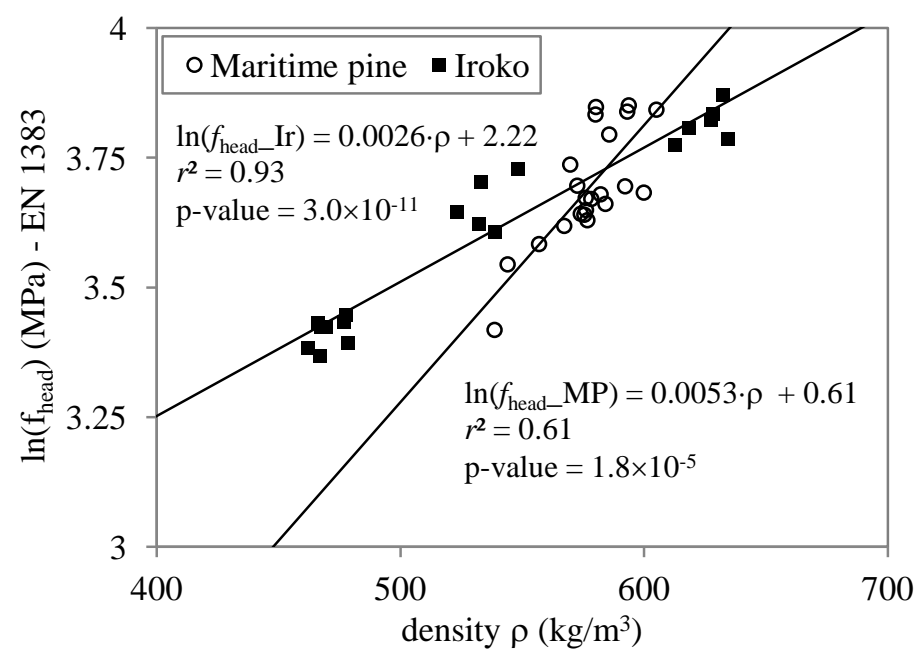

Figure 10: Correlation between headside pull-trough strength (obtained through EN 1383:2002) and density for Maritime pine and Iroko specimens. 


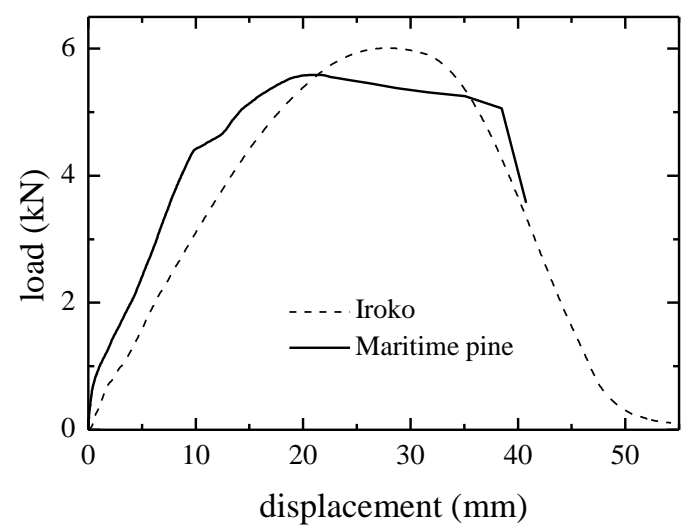

Figure 11: Averaged load-displacement curves for the headside pull-through tests considering both timber species: Maritime pine and Iroko.

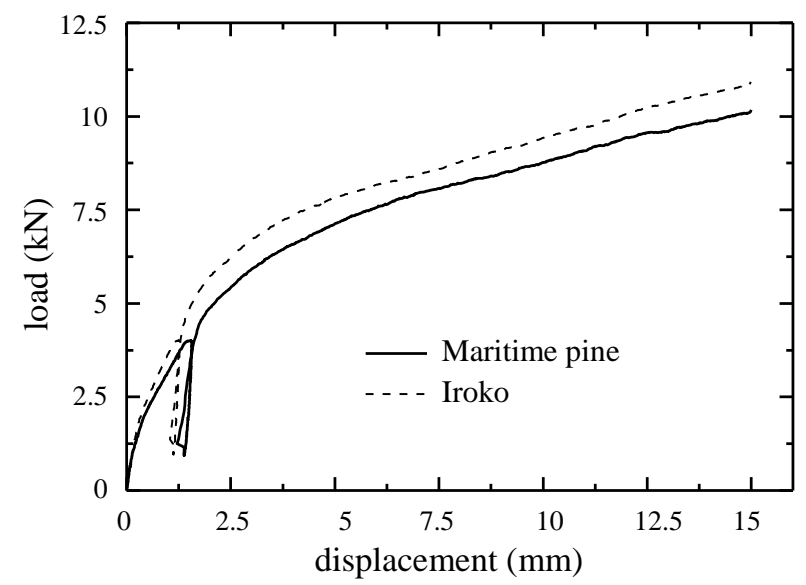

Figure 12: Load-displacement curves for the simple shear tests with Maritime pine and Iroko.

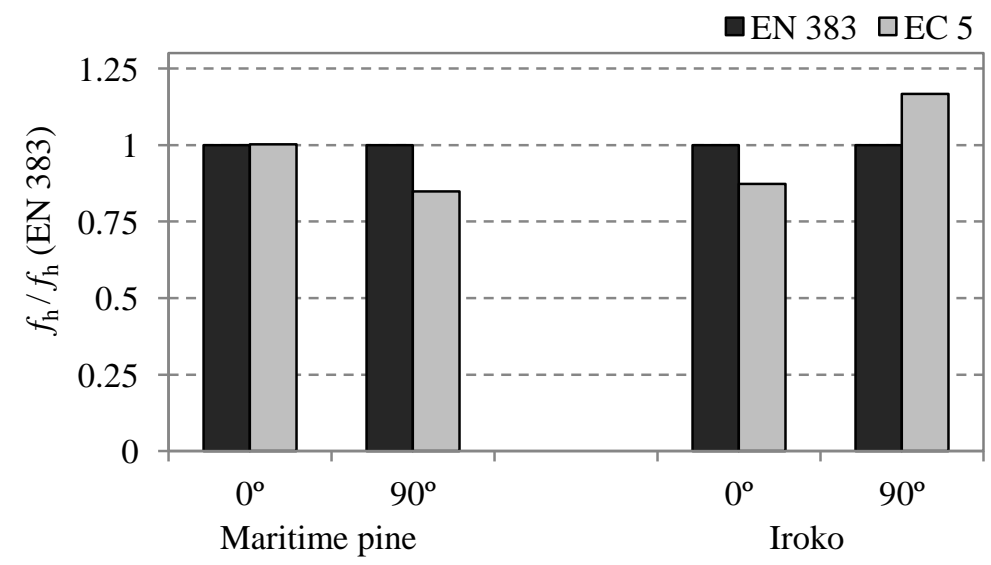

Figure 13: Comparison between results from embedment strength obtained through Eurocode 5 with experimental results made following the standard EN 383:2007. 


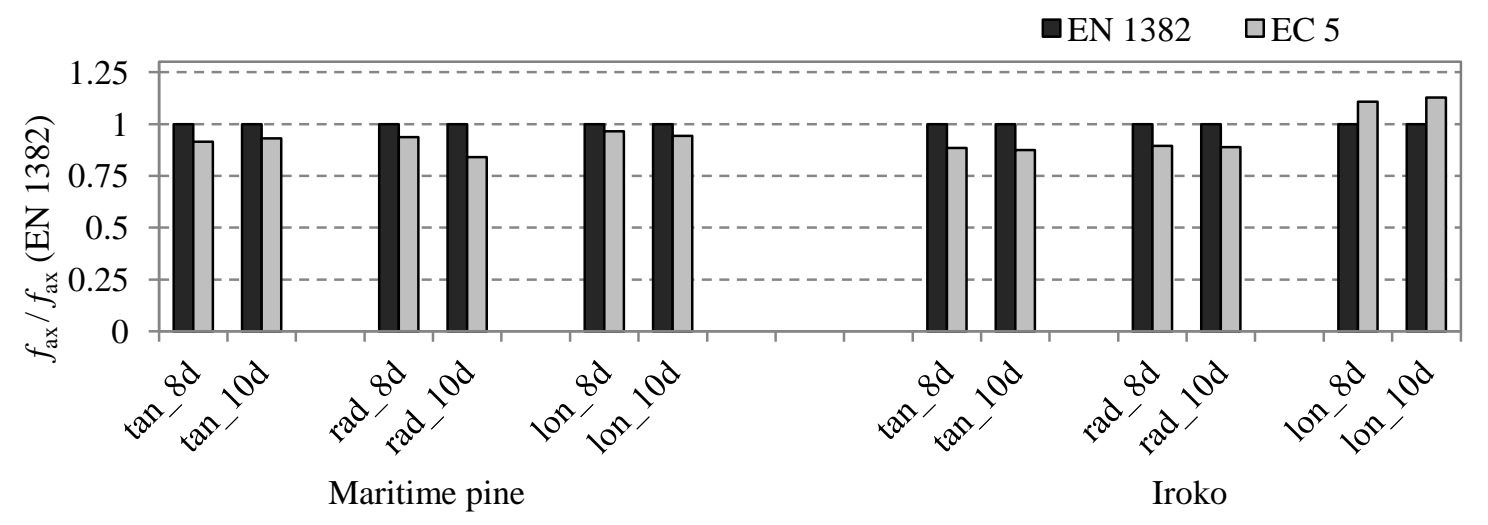

Figure 14: Comparison between results from withdrawal strength obtained through Eurocode 5 with experimental results made following the standard EN 1382:2002.

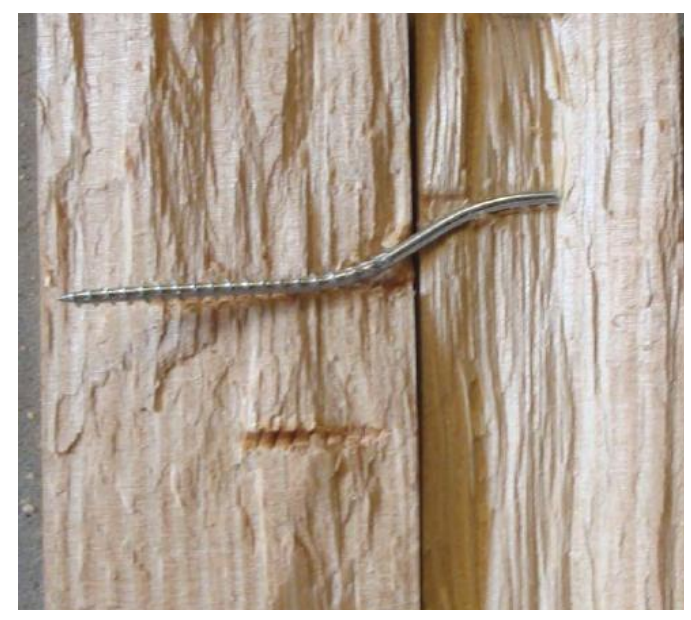

Figure 15: Failure mode of the tested connections, where is visible the local crushing of timber near the connection and the bending of the screw. 